\title{
Vertebral abnormalities in juvenile inland silversides Menidia beryllina exposed to terbufos during embryogenesis*
}

\author{
Douglas P. Middaugh, John W. Fournie, Michael J. Hemmer \\ U.S. Environmental Protection Agency • , Gulf Breeze Environmental Research Laboratory, Sabine Island, Gulf Breeze, \\ Florida 32561, USA
}

\begin{abstract}
Embryos of the inland silverside Menidia beryllina were exposed to a nominal concentration of $50 \mu \mathrm{g}$ terbufos $\mathrm{l}^{-1}$ during the first $5 \mathrm{~d}$ of embryogenesis. Silversides were maintained in clean dilute seawater until $37 \mathrm{~d}$ after hatching. Radiographs revealed compressed and fused vertebrae and dorsal-ventral misalignment of pre- and post-zygapophyseal processes. Histopathological examination of representative individuals exposed to terbufos during embryogenesis revealed various vertebral lesions ranging from small hyperostoses to almost complete fusion of some vertebrae
\end{abstract}

\section{INTRODUCTION}

Skeletal abnormalities are known to occur in fish embryos in response to environmental variables including water temperature (Garside 1959, Seymour 1959) salinity (Lee \& Williams 1970) and hypoxia (Alderdice et al. 1958). Complex effluents from a pulp mill and ore smelter caused vertebral abnormalities in the fourhorn sculpin Myoxocephalus guadricornis (Mayer et al. 1988). Pesticides, such as malathion, caused skeletal deformities in the embryos of estuarine fishes including the sheepshead minnow Cyprinodon variegatus and the Atlantic silverside Menidia menidia (Weis \& Weis 1976). Exposure of adult winter flounder Pseudopleuronectes americanus to DDT caused bone erosion and hemorrhaging at the vertebral junctures of developing embryos (Smith \& Cole 1973). Carbaryl, endrin, kepone and 2,4-dinitrophenol also caused skeletal defects in $C$. variegatus, $M$. menidia and $M$. beryllina (Weis \& Weis 1976, Couch et al. 1977, Hansen et al. 1977, Middaugh et al. 1988).

The organophosphorus pesticide, terbufos S[[(1,1dimethylethyl) thio]methyll0,0-diethyl phosphorodithi-

\footnotetext{
- Contribution No. 695, Gulf Breeze Environmental Research Laboratory

- Mention of commercial tradenames does not imply endorsement by the U.S. Environmental Protection Agency
}

oate used to control numerous agricultural pests (U.S. EPA 1983), has been detected in surface water and in ground water (U.S. EPA 1987). In a dose response study with embryonic Menidia beryllina, terbufos caused vertebral abnormalities at concentrations as low as 12.5 $\mu \mathrm{g}$ terbufos $\mathrm{l}^{-1}$ (Hemmer et al. 1990). The abnormalities, noted in newly hatched larvae, were attributed to toxicant-induced interference with normal development, and not to the probable neuromuscular action of compounds, such as kepone, that may induce severe contractions, thus fracturing vertebrae in juvenile fish (Couch et al. 1977).

In this study we exposed embryonic Menidia beryllina to terbufos and determined if vertebral abnormalities, observed at hatching, could also be detected in 5 wk-old fish maintained in clean water. The nominal exposure concentration of $50 \mu \mathrm{g}$ terbufos $1^{-1}$ used in this study, was based upon dose responses to terbufos defined by Hemmer et al. (1990). Vertebral abnormalities were examined by radiography and a histopathological evaluation of selected specimens was performed.

\section{MATERIALS AND METHODS}

Embryos. Inland silverside Menidia beryllina embryos were obtained from adults that spawned naturally in the laboratory at $5 \%$ salinity and $25^{\circ} \mathrm{C}$. 
The photoperiod was $20 \mathrm{~h}$ light: $4 \mathrm{~h}$ dark (light phase at 6.5 to $7.5 \mu \mathrm{E} \mathrm{m}^{-2} \mathrm{~s}^{-1}$ ). Embryos, deposited on a polyester substrate (Middaugh \& Hemmer 1984), were removed by pulling small sections of the substrate and attached embryos through a tightly closed pair of forceps, thus stripping the embryos from the spawning substrate. Embryos were placed in an evaporation dish, washed 5 times with sterile $5 \%$ seawater then placed under a dissecting microscope $(\times 20)$ for selection and enumeration of mid-blastula (Stage 8, see Lagler et al. 1977) individuals.

Exposure procedures. Eight glass culture dishes, $20 \mathrm{~cm}$ in diameter, were used for acetone controls and to expose embryos to terbufos. Stock solutions for acetone controls were prepared in four 1-l glass bottles containing $1 \mathrm{l}$ of $5 \mu \mathrm{m}$ filtered sterile seawater at $5 \%$ salinity and $25^{\circ} \mathrm{C} \pm 1^{\circ}$. Acetone $(50 \mu \mathrm{l})$ was added to each bottle, mixed for $20 \mathrm{~min}$ with a stir bar, and $500 \mathrm{ml}$ from each bottle decanted into each of 4 randomly selected culture dishes. A similar procedure was used in adding $50 \mu \mathrm{l}$ of a $1 \mathrm{mg} \mathrm{ml}^{-1}$ stock solution of terbufos, prepared in acetone, to each of four 1-1 glass bottles. After stirring, $500 \mathrm{ml}$ of the $50 \mu \mathrm{g}$ terbufos $\mathrm{I}^{-1}$ solution was poured from stock bottles into each of 4 randomly selected culture dishes. The remaining $500 \mathrm{ml}$ of test solution in each stock bottle was used for chemical analyses of initial terbufos concentrations.

Eight groups of 47 to 56 embryos, also randomly selected, were then placed into each of eight culture dishes to yield 4 seawater-acetone controls ( $A A, A B$, $\mathrm{AC}, \mathrm{AD})$ and 4 terbufos treatments (TA, TB, TC, TD).

Culture dishes were stacked by treatment and maintained in an incubator at $25^{\circ} \mathrm{C} \pm 1^{\circ}$ with a $14 \mathrm{~h}$ light: $10 \mathrm{~h}$ dark photoperiod (light phase at 15 to $17 \mu \mathrm{E} \mathrm{m}^{-2}$ $\mathrm{s}^{-1}$ ). A flat glass plate covered the top culture dish in each stack to reduce evaporation. Daily checks for dead embryos were made; they were removed and enumerated. Dissolved oxygen (DO) and $\mathrm{pH}$ were determined at the beginning of the exposure period and on Days 2, 4 and 5 .

After $5 \mathrm{~d}$ exposure, embryos were removed from each culture dish, washed 5 times with $5 \mu \mathrm{m}$ filtered sterile seawater at $5 \%$ salinity and $25^{\circ} \mathrm{C} \pm 1^{\circ}$, then placed in clean culture dishes containing 11 of $5 \%$ seawater and returned to the incubator.

Hatching and grow-out. Larvae began hatching $7 \mathrm{~d}$ after fertilization. On Day 8 all larvae from one of the acetone-controls (replicate $A B$ ) and one of the terbufos exposed groups (replicate TA) were microscopically examined for confirmation and quantification of the presence or absence of vertebral abnormalities.

On Days 8 to 10, 10000 to 15000 rotifers (Brachionus plicatilus) were added to each of the 6 remaining culture dishes. Gentle aeration was provided through Intermedic tubing connected to a compressed-air manifold. Larvae were then transferred to 7-1 glass containers, fed rotifers and Artemia nauplii until Day 17 when they were placed in six $0.66 \mathrm{~m}$ diameter $(160$ 1) fiberglass tanks. They were maintained at 5 to $8 \%$ salinity and $25^{\circ} \mathrm{C} \pm 1^{\circ}$ and fed Artemia nauplii daily until Day 37 when fish were fixed in $5 \%$ neutral buffered formalin. DO and $\mathrm{pH}$ were determined periodically during the grow-out phase.

Chemical analyses. The 4 initial $500 \mathrm{ml}$ terbufos samples were extracted twice with $100 \mathrm{ml}$ petroleum ether and concentrated to $1 \mathrm{ml}$. The 4 final $500 \mathrm{ml}$ terbufos samples were poured from exposure dishes into individual 1-1 glass bottles and extracted in a similar manner. The extracts of all samples were analyzed by electron capture gas chromatography utilizing a $182 \mathrm{~cm} \times 2 \mathrm{~mm}$ i.d. glass column, packed with $2 \%$ sp2100 on $100 / 120$ mesh Supelcoport, at a column temperature of $200^{\circ} \mathrm{C}$. The detertor was maintained at $300^{\circ} \mathrm{C}$ and quantitation was accomplished with a Hewlett-Packard 3357 Lab Automation system.

Radiographic and histologic procedures. All preserved fish were X-rayed with a Hewlett PackardFaxitron Series X-ray system set at $50 \mathrm{kVp}$ and $30 \mathrm{~s}$. Kodak Industrex M-2 film was used. Representative fish were selected for histopathological examination on the basis of radiographs showing what appeared to be fused vertebral centra or other abnormalities (Fig. 1).

Specimens processed for histopathological examination were decalcified in Cal-Ex ${ }^{*}$, dehydrated in a series of Technicon Dehydrant S-29 $9^{\oplus}$, and embedded in paraffin. Sagittal sections of whole fish were cut at $6 \mu \mathrm{m}$ and were stained with Harris' hematoxylin and eosin (Luna 1968). Sections were examined and photographed using an Olympus BH2 light microscope.

\section{RESULTS}

\section{Embryonic exposures}

Nominal and measured concentrations of terbufos from each replicate treatment are summarized in Table 1. Measured concentrations of terbufos on Day 1 of exposure were approximately $80 \%$ of the nominal

Table 1 Menidia beryllina embryos. Nominal and measured terbufos concentrations ( $\mu \mathrm{g} \mathrm{\textrm {J } ^ { - 1 }}$ ) in replicate treatments

\begin{tabular}{|cccc|}
\hline Treatment & Nominal & \multicolumn{2}{c|}{ Measured conc. } \\
conc. & Day 1 & Day 5 \\
\hline TA & 50.0 & 40.2 & 3.7 \\
TB & 50.0 & 39.2 & 3.3 \\
TC & 50.0 & 40.1 & 3.6 \\
TD & 50.0 & 39.6 & 2.1 \\
\hline
\end{tabular}


values. By Day 5, little terbufos could be detected in exposure solutions.

$\mathrm{DO}$ and $\mathrm{pH}$ values in acetone controls and terbufos treatments were similar during the $5 \mathrm{~d}$ embryonic exposure interval (Table 2).

Survival of embryos in acetone controls and terbufos treatments was similar (Table 3), and there was no evidence of terata in newly hatched larvae from the acetone control group sacrificed at hatching (replicate $A B)$. However, examination of newly hatched larvae from terbufos replicate TA revealed $46 \%$ with notochord abnormalities.

\section{Larval grow-out and radiographs}

$\mathrm{DO}$ and $\mathrm{pH}$ values in acetone controls and terbufos treatments were similar during the $37-d$ grow-out phase (Table 2).

Survival of the larval/juvenile stages of Menidia beryllina during the grow-out phase ranged from 71 to $83 \%$ in acetone controls and 72 to $90 \%$ in terbufos treatments (Table 3 ).

No vertebral abnormalities were detected in radiographs' of specimens from control groups. Vertebral abnormalities were found in 28 to $45 \%$ of surviving larvae exposed to terbufos during embryogenesis. These values are similar to the $46 \%$ incidence noted in newly hatched larvae from terbufos replicate TA (Table 3).
Characteristic radiographs of control and terbufos exposed individuals are shown in Fig. 1. Terbufos exposed individuals had compressed and fused vertebrae (Fig. 1b). Moreover, dorsal-ventral misalignment of pre-and post-zygapophyseal processes were often noted in radiographs, especially in the area immediately anterior and posterior to the first caudal vertebra. No abnormalities were observed in neural or hemal spines.

\section{HISTOPATHOLOGY}

A total of 22 acetone control and 25 terbufos exposed fish were examined histologically for vertebral lesions. Control fish all exhibited the characteristic amphicoelous, thin-walled vertebral centra comprised of acellular bone (Figs. 2 and 4). The notochord in control fish displayed the typical vestigial appearance.

Fish exposed to terbufos during embryogenesis however, exhibited various vertebral lesions (Fig. 3) ranging from small hyperostoses to almost complete fusion of vertebrae. Fig. 5 illustrates the simplest lesion which consisted of hypertrophy of the zygapophyseal processes. In other cases, the hypertrophy was more extensive and involved more of the central wall (Fig. 6). These lesions contained some proliferating osteoblasts and exhibited a prominent, cellular notochord in the central canal.

More extensive lesions exhibited longitudinal compression of vertebrae that were evident in radiographs

Table 2. Menidia beryllina. Mean dissolved oxygen (DO) $\mathrm{mg} \mathrm{l}^{-1}$ and $\mathrm{pH}$ measured during embryogenesis and larval grow-out phase. Standard deviation (SD)

\begin{tabular}{|c|c|c|c|c|c|c|c|c|c|c|}
\hline \multirow{2}{*}{$\begin{array}{l}\text { Days } \\
\text { (Life stage) }\end{array}$} & \multicolumn{5}{|c|}{ Acetone controls } & \multicolumn{5}{|c|}{ Terbufos exposed } \\
\hline & n & DO & $\mathrm{SD}$ & $\mathrm{pH}$ & SD & n & DO & $S D$ & $\mathrm{pH}$ & SD \\
\hline 1-6 (Embryo) & 16 & 8.1 & 0.3 & 7.7 & 0.2 & 16 & 8.1 & 0.3 & 7.7 & 0.1 \\
\hline $7-32$ (Larval) & 21 & 7.8 & 0.3 & 7.9 & 0.2 & 16 & 7.7 & 0.5 & 7.9 & 0.2 \\
\hline
\end{tabular}

Table 3. Menidia beryllina. Survival among treatments, abnormalities observed in notochord of newly hatched larvae, and occurrence of vertebral abnormalities from radiographs of 37 -d-old larvae. (-) no data

\begin{tabular}{|c|c|c|c|c|c|c|}
\hline \multirow[t]{2}{*}{ Replicate } & \multirow[t]{2}{*}{$\mathrm{n}$} & \multicolumn{3}{|c|}{ Survival $(\%)$} & \multicolumn{2}{|c|}{ Abnormalities (\%) } \\
\hline & & Embryo & Larvae & Overall & Notochord & Vertebrae \\
\hline \multicolumn{7}{|c|}{ Acetone control } \\
\hline $\mathrm{AA}$ & 51 & 82 & 71 & 58 & - & 0 \\
\hline $\mathrm{AB}$ & 51 & 88 & - & - & 0 & - \\
\hline $\mathrm{AC}$ & 47 & 85 & 83 & 70 & - & 0 \\
\hline $\mathrm{AD}$ & 49 & 95 & 81 & 78 & - & 0 \\
\hline \multicolumn{7}{|c|}{ Terbufos exposed } \\
\hline TA & 56 & 96 & - & - & 46 & - \\
\hline TB & 51 & 90 & 72 & 64 & - & 35 \\
\hline $\mathrm{TC}$ & 51 & 94 & 90 & 84 & - & 45 \\
\hline TD & 49 & 100 & 73 & 73 & - & 28 \\
\hline
\end{tabular}



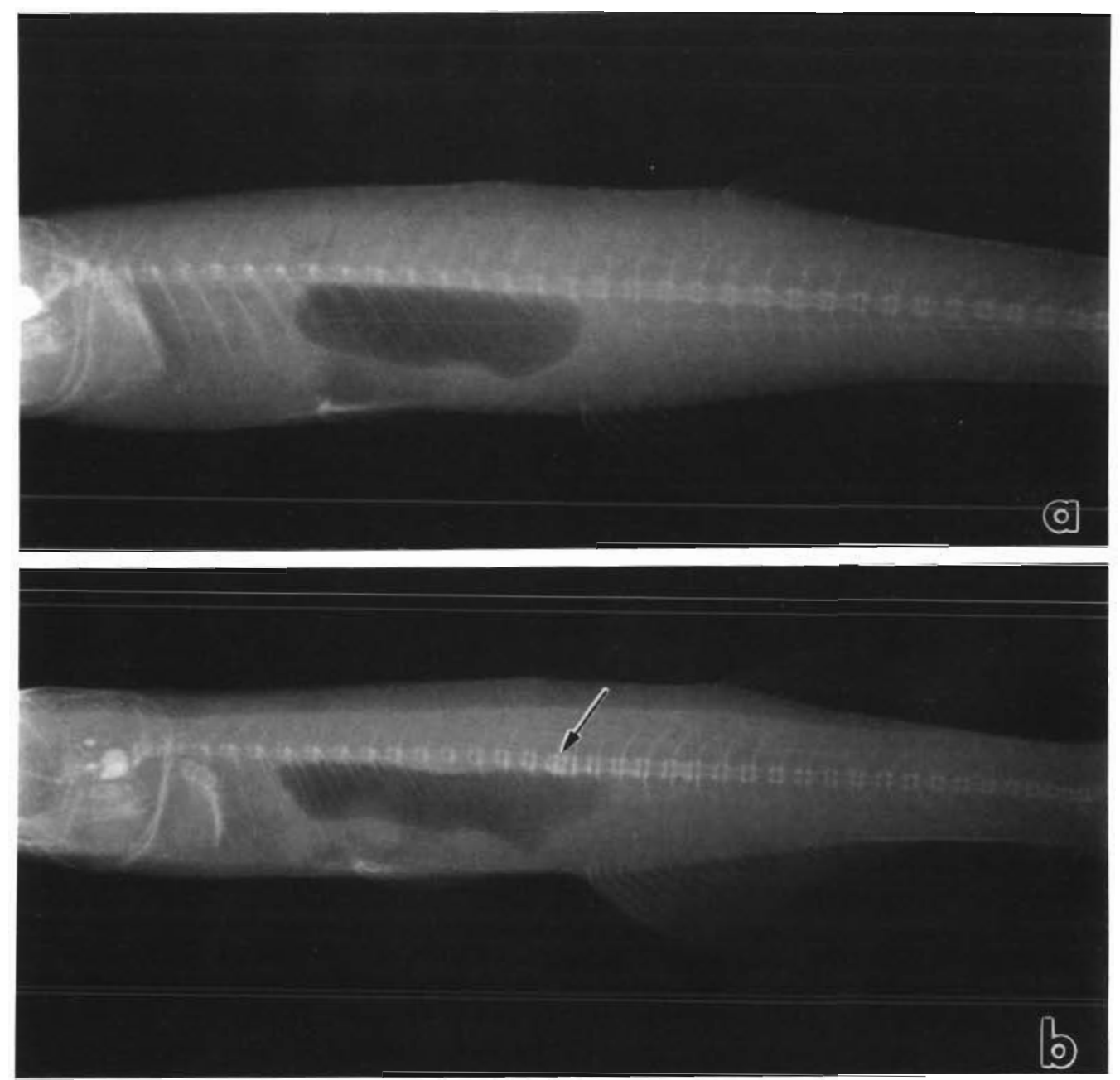

Fig. 1. Menidia beryllina. Radiographs of inland silversides. (a) Control fish showing normal biconical, thin-walled vertebral centra. (b) Fish exposed to $50 \mu \mathrm{g}$ terbufos $1^{-1}$ during embryogenesis. Note compressed and fused (arrow) vertebrae

(Fig. 1b) as well as in histological sections. Hypertrophied bone in these lesions was not restricted to the zygopophyseal region but included the entire central wall (Fig. 3). Formation of cellular bone was evidenced by the appearance of osteocytes in hypertrophied central walls (Fig. 7). Complete fusion of vertebral centra occurred in one of the specimens examined disrupting the normal form of the vertebra (Fig. 8). Proliferating fibroblasts, osteoblasts, and osteocytes were present in this lesion.

\section{DISCUSSION}

The vertebral abnomalities observed in larval Menidia beryllina at hatching in this study $46 \%$ incidence) were similar in appearance and incidence at hatching (27\%) to those noted by Hemmer et al. (1990) for embryonic $M$. beryllina exposed to initial terbufos concentrations of 12.5 to $100 \mu \mathrm{g} \mathrm{l}^{-1}$. Although the mechanism for expression is unknown, the abnormalities were attributed to toxicant interference with normal developmental processes, rather than tetany or severe neuromuscular contractions. Sporadic or chronic rigor in skeletal musculature has been proposed as the apparent mechanism for vertebral fractures in studies with older fish exposed to kepone (Couch et al. 1977) or organophosphate pesticides (McCann \& Jasper 1972, Kumar \& Ansari 1984).

The vertebral lesions induced in the inland silverside Menidia beryllina by exposure of embryos to terbufos are similar to the vertebral dysplasia in young sheepshead minnows Cyprinodon variegatus exposed to trifluralin (Couch et al. 1979). In both cases, the histopathological changes included marked hypertrophy of vertebral walls, a prominent cellular notochord, longitudinal compression of vertebrae, and fusion of some vertebral centra. Foci of proliferating fibroblasts, osteoblasts, and osteocytes were present in both 

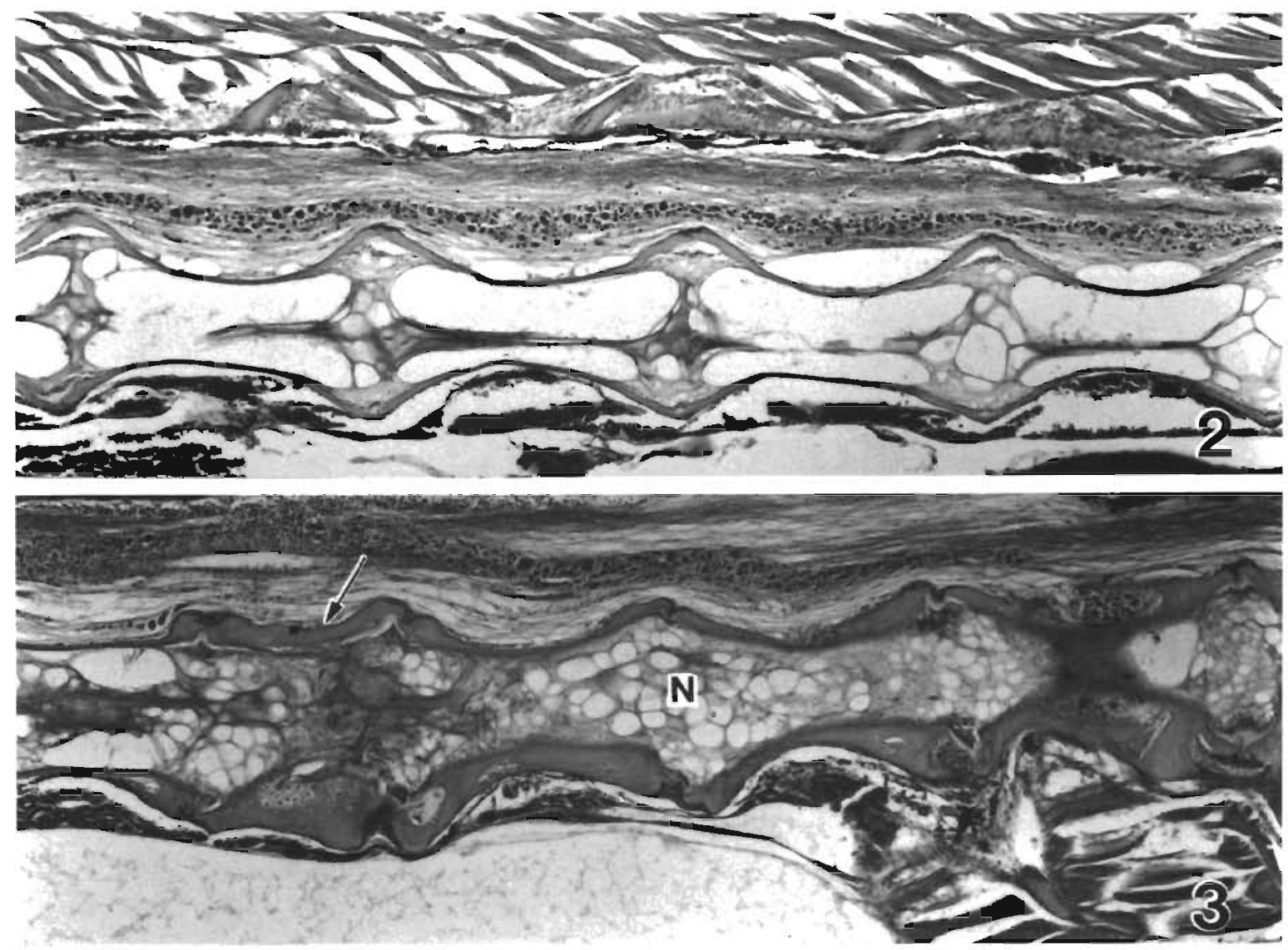

Figs. 2 and 3. Menidia beryllina. Sagittal histologic sections through whole fish; H\&E, $\times 110$. Fig. 2. Control fish showing normal, thin-walled vertebral centra and vestigial notochord. Fig. 3. Low magnification showing longitudinal compressed vertebra (arrow), marked hypertrophy of vertebral walls, and prominent notochord (N)

species, primarily in the zygapophyseal regions. However, there was not sufficient vertebral deformation in $M$. beryllina to cause all of the pathological effects described in C. variegatus (Couch et al. 1979). For example, we saw no extensive dorsal outgrowths of vertebrae compressing the spinal cord or ventral outgrowths compressing the mesonephric ducts draining the kidney as was the case in trifluralin-exposed $C$. variegatus.

Similar vertebral abnormalities were also reported in brown trout Salmo trutta and Atlantic salmon S. salar exposed to trifluralin (Wells \& Cowan 1982). Lesions in $S$. trutta were attributed to a herbicide containing trifluralin which was accidentally discharged into a stream and those in $S$. salar were the result of experimental laboratory exposures to trifluralin. In both species, the vertebral abnormalities included hypertrophy of vertebrae and kyphosis caused by longitudinal compression. Detailed comparisons between these salmonid vertebral abnormalities and the vertebral lesions in Menidia beryllina cannot be made because no histology was performed on the affected salmonids.
In conclusion, exposure to terbufos during embryogenesis produced vertebral lesions in Menidia beryllina remarkably similar to those noted by Couch et al. (1979) in Cyprinodon variegatus exposed to trifluralin. Although the chemical structure of these 2 compounds is quite dissimilar, the mechanism of action may be similar. The severe histopathological changes induced in $M$. beryllina may be the result of alteration of calcium metabolism in the corpuscles of Stannius and the ultimobranchial glands as suggested by Couch et al. (1979) for C. variegatus exposed to trifluralin. This alteration could account for the altered bone deposition and the apparent stimulation of osteogenic cells which occurred in both fishes. Moreover, because of notochord abnormalities observed in newly hatched $M$. beryllina larvae, it is possible that proliferating fibroblasts, osteoblasts and osteocytes are a secondary response to damage that occurred during embryogenesis. Further histologic studies of vertebral abnormalities induced by exposure to various chemicals may provide additional clues to the mechanisms responsible for these vertebral dysplasias. 

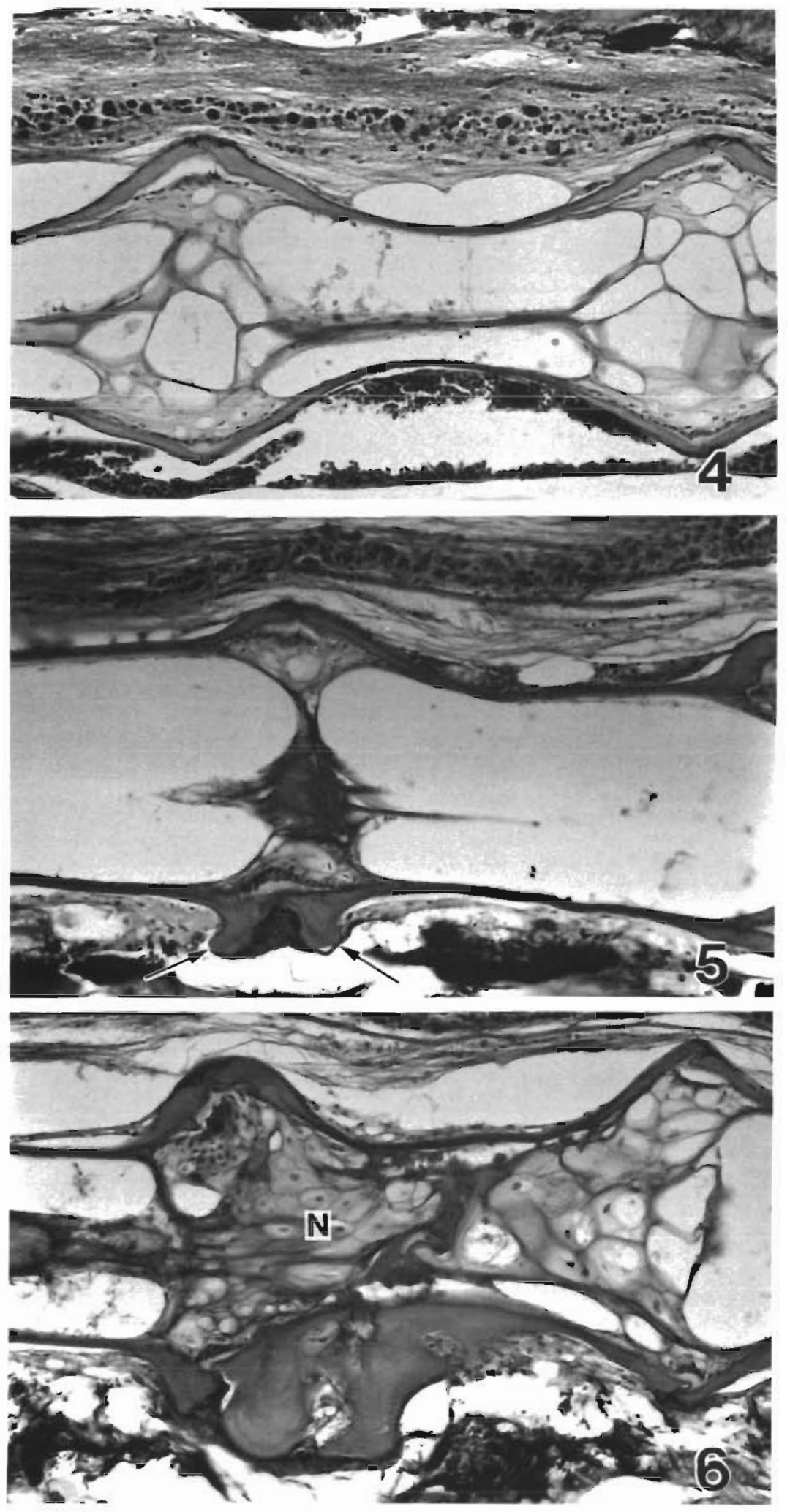

Figs. 4 to 6. Menidia beryllina. Sagittal histologic sections through. whole fish; $H \& E_{1} \times$ 220. Fig. 4. Higher magnification of control fish in Fig. 2 showing thin-walled vertebral centrum composed of acellular bone, Fig. 5. Fish exposed to terbufos showing hypertrophy of zygapophyseal processes (arrows). Fig. 6. Fish exposed to terbufos showing extensive hypertrophy of vertebral wall and prominent notochord (N) 

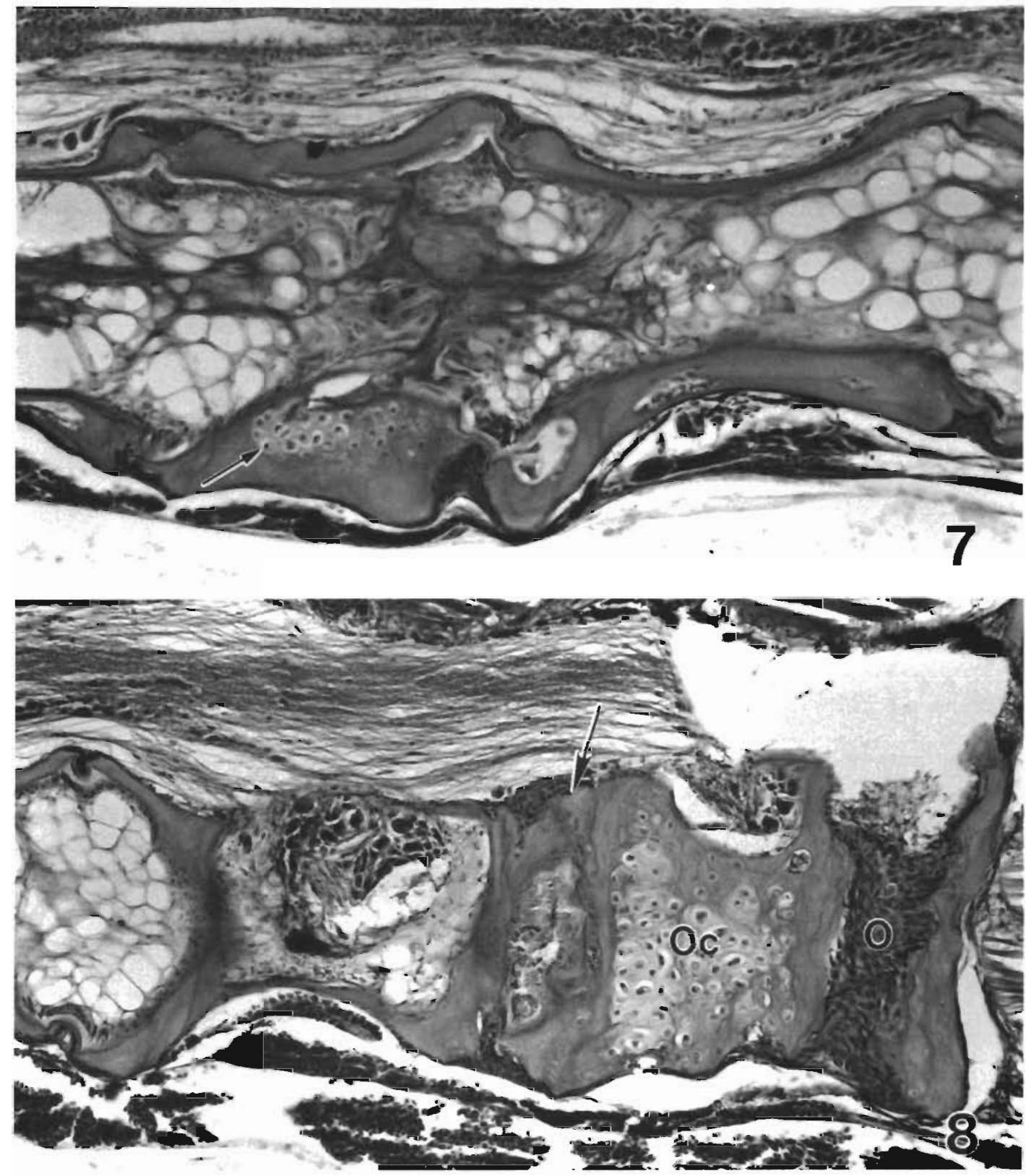

Figs. 7 and 8 . Menidia beryllina. Histologic section through whole fish exposed to terbufos; H\&E, $\times 220$. Fig. 7 . Higher magnification of Fig. 3 showing severe vertebral compression and proliferating bone containing osteocytes (arrow). Fig. 8 , Advanced vertebral lesion showing fused vertebrae (arrow). Note proliferation of fibroblasts and osteoblasts in zygapophyseal region $(\mathrm{O})$ and osteocytes $(\mathrm{OC})$ in bony matrix

Acknowledgements. We thank Lee A. Courtney, Steven S. Foss, and James $T$ Winstead for their technical assistance. Emile M. Lores conducted chemical analyses of terbufos and Maureen G. Stubbs typed the manuscript. William E. Hawkins reviewed the manuscript and provided helpful comments.

\section{LITERATURE CITED}

Alderdice, D. F., Wickett, W. P., Brett, J. R. (1958). Some effects of temporary exposure to low dissolved oxygen levels in Pacific salmon eggs. J. Fish. Res. Bd Can. 15: 229-249

Couch, J. A., Winstead, J. T., Goodman, L. R. (1977). Keponeinduced scoliosis and its histological consequences in fish. Science 197: 585-587

Couch, J. A., Winstead, J. T., Hansen, D. J., Goodman, L. R. (1979). Vertebral dysplasia in young fish exposed to the herbicide trifluralin. J. Fish. Dis. 2: 35-42

Garside, E. T (1959). Some effects of oxygen in relation to temperature on the development of lake trout embryos. Can. J. Zool. 37: 689-698

Hansen, D. J., Schimmel, S. C., Forester, J. (1977). Endrin: 
effects on the entire life cycle of a saltwater fish, Cyprinodon variegatus. J. Toxic envirl Hith 3: 721-733

Hemmer, M. J., Middaugh, D. P., Moore, J. C. (1990). The effects of temperature and salinity on Menidia beryllina embryos exposed to terbufos. Dis. aquat. Org. 8: 127-136

Kumar, K., Ansari, B. A. (1984). Malathion toxicity: skeletal deformities in zebrafish (Brachydanio rerio. Cyprinidae). Pestic. Sci. 15: 107-111

Lagler, K. F., Bardach, J. E., Miller, R. R., Passino, D. R. (1977). Ichthyology, 2nd edn. John Wiley and Sons, New York

Lee, C. L., Williams, W. D. (1970). Meristic differences between two conspecific fish populations in Australian salt lakes. J. Fish Biol. 2: 55-56

Luna, L. G. (1968). Manual of histologic staining methods of the Armed Forces Institute of Pathology, 3rd edn. McGraw Hill, New York

Mayer, F. L. Jr, Bengtsson, B. E., Hamilton, S. J., Bengtsson, A. (1988). Effects of pulp mill and ore smelter effluents on vertebrae of fourhorn sculpin: laboratory and field comparisons. Am. Soc. Test Mater., Spec. Tech. Publ 971: 406-419

McCann, J. A., Jasper, R. L. (1972). Vertebral damage to biuegiiis exposed to dcuiely loxic levels of pesticides. Trans. Am. Fish. Soc. 101: 317-322

Middaugh, D. P., Hemmer, M. J. (1984). Spawning of the tidewater silverside, Menidia peninsulde, (Goode and Bean) in response to tidal and lighting schedules in the laboratory. Estuaries 4: 139-148

$\begin{aligned} & \text { Responsible Subject Editor: Dr G. Peters, Hamburg, } \\ & \text { Germany }\end{aligned}$
D
Middaugh, D. P., Hemmer, M. J., Lores, E. M. (1988). Teratological effects of 2,4-dinitrophenol, produced water' and naphthalene on embryos of the inland silverside, Menidia beryllina. Dis. aquat. Org. 4: 53-65

Seymour, A (1959). Effects of temperature upon formation of vertebrae and fin rays in young chinook salmon. Trans. Am. Fish. Soc. 88: 58-69

Smith, R. M., Cole, C. F. (1973). Effects of egg concentrations of DDT and Dieldrin on development of winter flounder (Pseudopleuronectes americanus). J. Fish. Res. Bd Can. 30: 1894-1898

U.S. Environmental Protection Agency (1983). Guidance for the reregistration of manufacturing-use and certain enduse pesticide products containing terbufos as the active ingredient. EPA-540/RS-83-011. Office of Pesticides and Toxic Substances, Washington, D.C.

U.S. Environmental Protection Agency (1987). Health Advisories for 50 pesticides. PB 88-113543, Office of Drinking Water, Washington. D.C.

Weis. P., Weis, J. S. (1976). Abnormal locomotion associated with skeletal malformations in the sheepshead minnow, Cyprinodon varicgatus, exposed to malathion. Envirl Res 12: $196-200$

Wells, D. E., Cowan, A. A. (1982). Vertebral dysplasia in salmonids caused by the herbicide trifluralin. Envir. Pollut. (Ser. A) 29: 249-260

Manuscript first received: February 14, 1990

Revised version accepted: June 22, 1990 